\title{
Formation of the Professional Competence of the Future Elementary School Teachers on the Basis of Pedagogical Hermeneutics
}

\author{
Elena Vladimirovna Mandzhieva
}

Kalmyk State University, 358000, Republic of Kalmykia, Elista, Pushkina str., 11

\author{
Doi:10.5901/mjss.2015.v6n4s1p35
}

\begin{abstract}
Lead: The development of the education actualizes the need to solve the problem of evaluation of teacher professionalism, level of his/her professional competence, growth prospects, abilities of occupational rehabilitation. The country's need of teachers who can take a personally-humane stand towards the pupils and towards themselves. Also it makes the problem of increasing of a teacher's professional competence more acute. This problem becomes of special significance due to the spread of ideas of education humanization and humanitarization and pedagogical hermeneutics.
\end{abstract}

Keywords: competence, pedagogical competence, bachelor, pedagogical education, pedagogical hermeneutics.

\section{Introduction}

Under the conditions of the modern Russian education reforming there appears the growing need for a teacher who can work under the new conditions, who can contribute to the comprehensive development of the growing generation by means of ethnocultural connotations. The formation of teachers' competence takes a special place in the training of the future teachers (E. F. Zeer, I.A.Zimnyaya, N.V.Kuzmina, A.V.Khutorskoi). Pedagogics consider this phenomenon not only from the professional viewpoint, the competence approach is defined as a new paradigm of the result of education.

The concept of "competence" has appeared in the psychological-pedagogic ??? quite recently. Thus, at the end of 1960s - at the beginning of 1970s in the western science (and at the end of 1980s - in the Russian science) there appears a special direction - a competence approach in education under which the total of general principles in the determining of the educational goals, content of education, organisation of the educational process and evaluation of the educational results are understood.

Competence approach in education is understood as the development and assessment of different competences through the broadening of the corresponding tasks by the subject. Competence approach in the results ??? assessment is a complex of educational technologies and conditions which allows to make an objective assessment of a student's competence level which the student has reached as the result of the performing educational activity.

The most famous scientist among those who studied this question is D. Raven, who determines the competence as a specific ability necessary for the effective implementation of a definite action in the definite application; this ability includes narrowly-specialized knowledge, special subject skills, ways of thinking as well as the understanding of the responsibility for one's own actions [1].

I. A. Zimnyaya understands competence as an acute, formable personal quality which is based upon the knowledge, as intellectually and personally conditioned social-professional feature of a human. She points out the following components in the structure of the competence: a) readiness to express competences (motivational aspect) where the readiness is considered as a mobilization of the subject forces; b) possession of the knowledge of the competence content (cognitive aspect); c) experience of the competence expression in different standard and nonstandard situations (behavioural aspect); d) attitude towards the competence content and object of its application (axiological aspect); e) emotional-volitional regulation of the process and result of competence expression [2].

According to the opinion of $\mathrm{V}$. A. Mizherikov, competence is the total of the essential knowledge and qualities of a person, which allow to solve different issues of the corresponding sphere of knowledge, scientific or practical activity professionally and effective. Also he determined several types of competences.

Communicative competence is the ability of a person to perform speech acts and to be able to listen. The following qualities which provide the communicativeness of an individual are defined as comprehensive: ability to put questions and give clear answers to them, to listen attentively and actively discuss current problems, to comment the expressions of the interlocutors and give them critical evaluation, present arguments to one's own opinion. 
Social competence is an integral personal formation which includes two components: a) cognitive-behavioural which relates to the social activity that is significant for a subject; it includes the knowledge of the society and oneself in the society, ability to integrate them, skills of social interaction, meaningful ways to behave in difficult situations; $b$ ) motivation-personal, which reflects the attitude to the society, expressed in motivation, values and personal qualities; it includes motives for self-development and achievements, social responsibility, meaningfulness of life as a leading motivational tendency of a person.

Professional competence is the teacher's possession of the necessary knowledge, skills and abilities which determine the formedness of the pedagogic activity, pedagogic communication and the personality of a teacher as a bearer of certain values, ideals and pedagogical conciousness. The sum total of knowledge, experience, skills of flexible possession of pedagogic practical technology, finding of the best ways of influencing a student taking into account his needs and interests, rights and free choice of ways of activity and behaviour.

\section{Literature Review}

Some scientists think that the reason for the introduction of the concept of "professional adequacy" is conditioned by the width of its content, integrative characteristic which combines such widely used concepts as "professionalism", "qualification", "professional skills" etc. However the scientists underline the fact that the concept under study is often equated with the concept "competence". According to their opinion, adequacy is a sort of personal characteristic, and competence is the sum total of the certain professional and functional characteristics.

The professional adequacy of a teacher is understood as the unity of his/her theoretical and practical readiness to perform pedagogic activity. Adequacy is considered as one of the stages of professionalism which forms the basis for the pedagogic activity of a teacher. Teacher's adequacy is interpreted as an ability of a person to solve different types of pedagogic tasks of different levels.

The category of the "professional competence" of an elementary school teacher is considered by Sorokin T. M. as a collective concept which defines the originality of a person as a teacher and children's psychologist. It is based on the teacher's conceptual awareness of his/her pedagogic abilities, peculiarities of the group of children, prospects of development of its originality of the society (current characteristics of the social phenomena, peculiarities of the parents' group etc.). Such a conceptual awareness defines the professional flexibility of a teacher for selection (not copying!) of pedagogic technologies, methods which allow successfully to develop the main goal - to create conditions for the positive development of the personality of an elementary pupil.

In her investigation a professional competence of the future elementary school teacher is interpreted as the dynamic, process side of his/her professional training, characteristics of the professional growth, professional changes both motivational and pragmatic. He considers the professional competence as the phenomenon of the gradual professionalization of the future teacher. At the same time the concept "adequacy" defines the professional activity of the senior person more clear. Besides, it brings a definite specific character into the concept of "professional competence" this is an integral professionally-personal characteristic of the future teacher as well as the sphere of application of his/her professional abilities.

Professional competence of an elementary school teacher is of special nature, it is multidisciplinary. The central core of this concept of the future elementary school teachers' professional training is the total change of the role and content of the psychological training, which should be integrated together with all aspects of the study in a single developing space which is professionally significant for a student. Such an activity of the future teacher contributes to his/her current level of professional competence which allows to perform difficult professional activity of forecasting goals and tasks of the children's mental growth in the process of education, creating effective conditions for solving such tasks, developing diagnostic programmes including those basing on the discipline material.

Student's adequacy is a new quality which is acquired in the process of study. It is connected with his/her ability to solve vital tasks and problems, basing on the knowledge, skills, experience and system of values [4].

The following essential characteristics of adequacy are pointed out: 1) it has pragmatic character of the generalized skills in combination with the specific skills and knowledge in certain spheres; 2) it reveals in the ability to choose basing on the adequate assessment of oneself in a certain situation.

The concept of "adequacy" includes the skills and knowledge related to the wide spheres of culture and activity: informational, communicational, everyday etc. Adequacy is a formed personal quality (set of qualities) which allows to solve problems and typical tasks, appearing in the real life situations with the help of knowledge, educational or life experience, values and inclinations.

Along with the concept of "adequacy" the concept of "competence" is used. This concept also has different 
description in different sources. The word competence derived from the Latin word "competo" meaning "achieve, comply, fit". In vocabularies and scientific literature "competence" is explained in different ways: 1) knowledge, skills, experience, theoretical-practical readiness to use knowledge; range of questions which someone is well aware of; 2) The total of the questions which the given subject well knows and has his/her own experience in these questions [5].

Adequacy and competence according to V. A. Matveeva, are complementary and mutually conditioned concepts: a competent person who has competence cannot realise it to the full extent and in the socially significant aspects.

The authors of the definition dictionary under the editorship of D. I. Ushakov for the first time tried to prove differences between the concepts of adequacy and competence: "Adequacy" - awareness, authoritativeness. "Competence" - a range of questions, phenomena in which the given person has authoritativeness, knowledge, experience, range of powers" [6].

Scientists E. F. Zeer ad E. E. Symanyuk define competences as an integrative wholeness of knowledge, abilities and skills which contribute to the professional activity as the ability of a person to realize his/her adequacy practically. The note that the structure of competences includes motivational and emotional-volitional component besides the pragmatic knowledge, abilities and skills. Moreover, experience is also of great importance - integration into the whole of the separate actions, methods and ways of solving tasks, which a person has acquired. Flexible competences of the wide range of use are called "key competences". Key competences define the flexibility of a specialist [7].

A special role in the professional training of a future teacher is played by the hermeneutic approach which, being under the modern sociocultural conditions, is not only to implement ready scientific projects but also to interpret social order, while being in the text semantic field of the innovative search, as well as compare priorities of the social values and norms with cultural and personal senses, without the clichéd patterning and depersonalization of the knowledge of a human [8].

In the process of the students' professional competence formation it is of the great significance to base on the humanitarian mechanisms of education which are represented by the key categories of the hermeneutic "apprehension", "understanding", "interpretation".

Pedagogic hermeneutic (definition by A. F. Zakirova) is the theory and practice (science and art) of the explanation and interpretation of the pedagogic knowledge, fixed in the texts of different genres; the aim of the theory and practice is the profound understanding taking into account sociocultural traditions, reflexive apprehension of the emotional-spiritual experience of the mankind and personal spiritual experience of the subject of understanding [9].

Hermeneutic approach in the Pedagogics is turned to the problem of formation of personal senses, to theaxiological aspects of the pedagogic activity [10]. It is notable, that task of creation of the new axiological system of the society - an open, variable, spiritually and culturally rich, interlocutory, tolerant, one that unify modern socially significant values and attitudes with the brand new Russian traditions - is marked today as one of the directions of the Russian educational policy. This proves the urgent character and timeliness of the scientific investigations of pedagogic hermeneutics which solves the task of achieving ideals of inwardness on the basis of the humanistic understanding of the world.

\section{Discusssion}

Nowadays the hermeneutic is popular as a methodology of the academic study of different phenomena. The basis of the hermeneutic is the idea of influence of the mechanisms of reading and interpretation of the information on the human conciousness in general, on the ways of thinking and understanding of the world as well as (indirectly) on the other types of activity including forecasting, modelling, designing, diagnostic and pedagogic communication, formation of the professional competence.

Hermeneutic approach to the understanding of the pedagogic reality is the method of countering commodification and depersonification of the knowledge of a human, resistance of the threat of "technological terror" in education. The key idea of the pedagogic hermeneutic is the development of the human self-conciousness in the process of reading and interpretation of information, humanitarization of his/her thinking and understanding of the world, professional establishing, formation of the competence in the sphere of one's own activity.

\section{Conclusion}

Thus, the understanding, interpretation and formation of the professional competences means understanding their paradigm level, i.e. the components of their objective meanings - rules and laws which reflect the stable and repeating cause-and-effect relationship of the interpreting knowledge as well as the narrative level of knowledge and life meanings 
implemented in it, i.e. ways of certain connection, compatibility of the concepts in the real practice and in narrative texts respectively. The special stimulation of the sense formation creates favourable conditions for the search, definition and understanding of the connections between the objective meanings of the pedagogic knowledge, universal culturalpedagogic senses and personal meanings. This contributes to the revealing and activation of the humanistic potential of the pedagogic activity.

\section{References}

Raven D., 2002. Adequacy in the modern society: influence, development and implementation. Moscow: "Kogito-Tsentr", pp: 396.

Zimnyaya I.A., 2006. Adequacy approach. What is its place in the system of the modern approaches and problems of education. (Theoretic-methodological aspect). Today's higher education. 4: 20-27.

Angelovski K., 1991. Teachers and innovations. Book for a teacher. Moscow: Prosveshchenie, pp: 159.

Investing in Education. Analyses of the 1999 World Education Indicators. 225. Knight J. L., 2003. Internationalization remodelled: Responding to new realities and challenges.

Hoffmann T., 1999. The meanings of competency. Journal of European Industrial Training, 23 (6): 275-285.

Big definition dictionary of the Russian language, 2009. Moscow: Publishing house Astrel, AST, pp: 1280.

Zeer, E. F. and E. E. Symanyuk, 2005. Competence approach to the modernisation of the professional education. Higher education in Russia. 4: 22-28.

Zakirova A. F., 2001. About the role of the pedagogic hermeneutic in the humanization of the education. Education and Science. 3 (9): $107-117$

Zakirova A. F., 2004. Hermeneutic interpretation of the pedagogic knowledge. Pedagogics. 1: 32-42.

Bollnow O.F., 1982. Studying Hermeneutic. Frieburg; Munchen. 